Nat. Hazards Earth Syst. Sci., 18, 599-611, 2018

https://doi.org/10.5194/nhess-18-599-2018

(C) Author(s) 2018. This work is distributed under the Creative Commons Attribution 4.0 License.

\title{
The use of genetic programming to develop a predictor of swash excursion on sandy beaches
}

\author{
Marinella Passarella ${ }^{1}$, Evan B. Goldstein ${ }^{2}$, Sandro De Muro ${ }^{1}$, and Giovanni Coco ${ }^{3}$ \\ ${ }^{1}$ Department of Chemical and Geological Sciences, Coastal and Marine Geomorphology Group (CMGG), \\ Università degli Studi di Cagliari, 09124 Cagliari, Italy \\ ${ }^{2}$ Department of Geological Sciences, University of North Carolina at Chapel Hill, 104 South Rd, Mitchell Hall, \\ Chapel Hill, NC 27599, USA \\ ${ }^{3}$ School of Environment, Faculty of Science, University of Auckland, Auckland, 1142, New Zealand
}

Correspondence: Marinella Passarella (marinella.passarella@unica.it)

Received: 23 June 2017 - Discussion started: 4 October 2017

Revised: 11 December 2017 - Accepted: 20 December 2017 - Published: 28 February 2018

\begin{abstract}
We use genetic programming (GP), a type of machine learning (ML) approach, to predict the total and infragravity swash excursion using previously published data sets that have been used extensively in swash prediction studies. Three previously published works with a range of new conditions are added to this data set to extend the range of measured swash conditions. Using this newly compiled data set we demonstrate that a ML approach can reduce the prediction errors compared to well-established parameterizations and therefore it may improve coastal hazards assessment (e.g. coastal inundation). Predictors obtained using GP can also be physically sound and replicate the functionality and dependencies of previous published formulas. Overall, we show that ML techniques are capable of both improving predictability (compared to classical regression approaches) and providing physical insight into coastal processes.
\end{abstract}

\section{Introduction}

Wave run-up is the final expression of waves travelling from deep to shallow water and is directly associated with coastal hazards like flooding or erosion. Wave run-up height can be defined from water level elevation time series at the shoreline $\eta(t)$ as the sum of two distinguished components: the wave set-up (the temporal mean of the time series $\langle\eta\rangle$ relative to the still water level) and the swash $\eta^{\prime}(t)$ (the vertical fluctuation of the water level around the wave set-up). Understanding and predicting swash characteristics is critical for researchers seeking to understand the dynamics of fluid motions and sediment transport in the swash zone (e.g. Elfrink and Baldock, 2002; Masselink and Puleo, 2006), and for managers and practitioners addressing hazard setbacks, risk and coastal vulnerability (e.g. Bosom and Jiménez, 2011; Vousdoukas et al., 2012). Wave run-up (and therefore swash excursion) is a key component used to evaluate inundation hazards and vulnerability to storm impacts (e.g. Bosom and Jiménez, 2011; Stockdon et al, 2007; Serafin et al., 2017). Stockdon et al. (2007) found that the wave action counted for about $48 \%$ of the maximum total water level during two hurricanes along the USA coast. The problem of accurate predictions of wave run-up and swash on sandy beaches has been a research topic for over 50 years but today we still struggle to provide reliable quantitative predictions.

The first predictors of these phenomena were developed in the context of coastal structures (Miche, 1951; Hunt, 1959) and the formulas proposed, usually developed for steep slopes and under the assumption that run-up motions reflect the standing component of the incident wave field. Overall these formulas suggested a dependence of the uprush elevation on wave steepness and structure slope. A variety of predictors have since then been developed for vertical run-up $(R)$ and swash $(S)$ on sandy beaches (e.g. Guza and Thornton, 1982; Holman and Sallenger, 1985; Holman, 1986; Ruessink et al., 1998; Stockdon et al., 2006), with details of the parameterizations depending on different combinations of deepwater significant wave height $\left(H_{\mathrm{s} 0}\right)$, deepwater wavelength $\left(L_{0}\right)$ and beach slope $(\beta)$. Guza and Thor- 
ton (1982) proposed a linear relationship between the significant run-up $\left(R_{\mathrm{s}}\right)$ and $H_{\mathrm{s} 0}$ :

$R_{\mathrm{s}}=c H_{\mathrm{s} 0}$,

where $c=0.7$. Guza and Thornton (1982) also first distinguished between infragravity and incident swash components, indicating that the swash component related to low frequencies (infragravity, $R_{\mathrm{Ig}}$ ) depends only on significant wave height (therefore excluding the beach slope), while the incident component can saturate as a result of the dissipative processes occurring in the surf zone. Their findings were later confirmed by several other studies, although different dependencies on environmental parameters were suggested (e.g. Holman and Sallenger, 1985; Ruessink et al., 1998).

Holman and Sallenger (1985) studying an intermediate to reflective beach (Duck, North Carolina, USA) described $R_{\mathrm{s}}$ as

$R_{\mathrm{S}}=c \xi_{0} H_{\mathrm{s} 0}$,

where $c$ is a constant, $H_{\mathrm{s} 0} / L_{0}$ is the wave steepness and

$\xi_{0}=\frac{\tan \beta}{\sqrt{H_{\mathrm{s} 0} / L_{0}}}$,

where $\beta$ is the foreshore beach slope and $\xi_{0}$ is the surf similarity index which is also often used for beach classification - beaches are classified as dissipative for values of $\xi_{0}<0.23$, reflective for $\xi_{0}>1$ and intermediate (Short, 1999).

Stockdon et al. (2006) used 10 experiments from different locations to generate new parameterizations of wave run-up on natural beaches. The $2 \%$ exceedance value of wave run up $R_{2}$ was defined as

$R_{2}=1.1\left(\langle\eta\rangle+\frac{S_{\mathrm{Tot}}}{2}\right)$,

where $\langle\eta\rangle$ is the maximum set-up elevation and $S_{\text {Tot }}$ is the total swash defined as

$S_{\text {Tot }}=\sqrt{\left(S_{\text {in }}\right)^{2}+\left(S_{\text {Ig }}\right)^{2}}$,

where $S_{\text {in }}$ and $S_{\text {Ig }}$ are the incident and infragravity components of swash. Stockdon et al. (2006) used regression techniques to obtain relationships for $S_{\mathrm{in}}$ and $S_{\mathrm{Ig}}$ :

$S_{\text {in }}=0.75 \beta \sqrt{H_{0} L_{0}}$,

and

$S_{\mathrm{Ig}}=0.06 \sqrt{H_{0} L_{0}}$.

Stockdon et al. (2006) is the most commonly used empirical parameterization of run-up but, as can be noted by comparing Eqs. (6) and (7), the beach slope is missing from the predictor of the infragravity component of swash. The dependency (or not) of $S_{\text {Ig }}$ on beach slope is a topic that has been debated but not solved and some authors (e.g. Ruessink et al., 1998) have indicated that infragravity swash is independent from the beach slope, while a weak dependence on beach slope has instead been reported by others (e.g. Ruggiero et al., 2004). Cohn and Ruggiero (2016) suggested a bathymetric control of the infragravity swash component through 1-D and 2-D numerical simulations performed using Xbeach (where incident swash contribution is excluded) and compared them with previous formulas (Ruggiero et al., 2001; Stockdon et al., 2006) and field data on dissipative beaches. They suggested that beach morphology ( $>-2 \mathrm{~m}$ m.s.l.) influences the infragravity component of run-up more than the nearshore morphology $(<-2 \mathrm{~m}$ m.s.l.) and indicated that including the foreshore beach slope in the formulation of $S_{\text {Ig }}$ improves predictability. Overall, it remains unclear if and when $S_{\mathrm{Ig}}$ depends on beach slope. In addition the similarity in the temporal scales of wave set-up and infragravity motions could also be a confounding factor in measurements. Finally, a number of other studies have also proposed other predictors that introduce other parameters to account for the cross-shore wind component and the tidal range (Vousdoukas et al., 2012), the presence of nearshore sandbars (Cox et al., 2013) or the sediment mean grain size for the case of gravel beaches (Poate et al., 2016). The above-mentioned empirical run-up formulas have been developed primarily with classic regression approaches (e.g.; Ruessink et al., 1998; Ruggiero et al., 2001; Stockdon et al., 2006; Vousdoukas et al., 2012).

Because of the importance of accurate predictions of swash excursion, the predictors provided by Stockdon et al. (2006) have been tested by various authors on beaches ranging from reflective to dissipative (e.g. Vousdoukas et al., 2012; Cohn and Ruggiero, 2016; Atkinson et al., 2017). Predictions using Stockdon et al. (2006) are certainly sound (especially considering the task of generating a universal formula for vertical swash excursion), even though differences between measurements and predictions, possibly associated with local conditions, are inevitably found. More importantly, the regression approach of multiple data sets first proposed by Stockdon et al. (2006) paves the way for our working hypothesis: can powerful data-driven techniques be used to provide robust, reliable and realistic predictions of swash excursion?

When enough data exist, machine learning (ML) is a viable approach to regression problems. ML is a subdiscipline of computer science focused on techniques that allow computers to find insightful relationships between variables involved in swash processes, learning at each iteration (algorithm training and validation) from the provided data set. A key goal of ML is to develop predictors that are generalizable (able to describe the physical process beyond the training data set itself). Many different data-driven techniques fall under the purview of machine learning (e.g. decision trees, artificial neural networks, Bayesian networks and evolutionary computation), all of which have shown applicability in coastal settings (e.g. Pape et al., 2007; Knaapen 
and Hulscher, 2002; Dickson and Perry, 2016; Yates and Le Cozannet, 2012). Previous machine learning work has focused on predicting run-up and swash, but only for engineered structures, impermeable slopes and/or for laboratory experiments (e.g. Kazeminezhad and Etemad-Shahidi, 2015; Bonakdar and Etemad-Shahidi, 2011; Bakhtyar et al., 2008; Abolfathi et al., 2016) and not on natural beaches apart from Vousdoukas et al. (2011), which used artificial neural networks (ANNs) for shoreline contour elevation (which includes the wave run-up), on a natural beach in Portugal. In this study we focus on the use an evolutionary technique, genetic programming (GP), to solve the symbolic regression problem of developing new, optimized swash predictors.

In this contribution we first develop a swash excursion predictor using the original data set of Stockdon et al. (2006), one of the most comprehensive studies in this area of research. In addition, we use data from Guedes et al. (2011, 2012, 2013) and Senechal et al. (2011) to broaden the parameter space and to test the new swash equations. The data used in this work cover a broad range of swash excursion including extreme wave conditions (maximum $H_{0}=6.4 \mathrm{~m}$ in Senechal et al., 2011). High swash excursions, generated by extreme storms, are of particular interest when studying coastal hazards because they relate to flooding, beach and dune erosion (Bosom and Jimenez, 2011; Stockdon et al., 2007). The new ML-derived results are also compared to the most widely used predictors from Stockdon et al. (2006). Finally, we discuss the physical interpretation of the GP predictors and how we can use ML to gain knowledge of physical processes related to the infragravity swash component.

\section{Data}

This work is based on two published video image-derived run-up data sets -13 field experiments in total. The first data set (referred to here as the "original data set") is composed of 491 swash measurements from 10 experiments aggregated by Stockdon et al. (2006). The second data set (referred to here as the "new data set") consists of 145 swash measurements compiled for this work from three experiments performed by Guedes et al. $(2011,2013)$ and Senechal et al. (2011). For details about the access to data, the reader is referred to the section data availability.

The compiled data set of total swash is plotted in Fig. 1. The compilation of a large data set deriving from 13 different experiments requires merging data collected using different techniques and equipment. Details of each experiment can be found in the original references. Looking at the environmental forcing conditions, Fig. 1 shows that the original and new data set cover similar ranges of beach slope, while they differ in significant wave height (the new data set includes wave heights over $6 \mathrm{~m}$ ) and peak period (the original data set includes more short period waves).
Both data sets include recordings of infragravity swash $\left(S_{\mathrm{Ig}} ; \mathrm{m}\right)$, total swash $\left(S_{\text {Tot }} ; \mathrm{m}\right)$, beach slope $(\beta)$ and associated offshore wave characteristics: significant wave height $\left(H_{0} ; \mathrm{m}\right)$ and peak period $\left(T_{\mathrm{p}} ; \mathrm{s}\right)$. From these measurements the offshore significant wavelength $\left(L_{0} ; \mathrm{m}\right)$ wave steepness $\left(H_{0} / L_{0}\right)$ and Iribarren number $\left(\xi_{0}\right)$ are calculated. Experiments are located in North America, Europe and Oceania and cover a large range of the environmental condition (see Table 1 and Fig. 1).

Both data sets include all beach types, from dissipative to reflective. The two data sets also have a similar range of $S_{\text {Tot }}$ (although the original data set records a larger swash, 0.2$3.3 \mathrm{~m}$ vs. $0.24-2.5 \mathrm{~m}$ of the new data set), $S_{\text {Ig }}$ (about 0.2 $2.4 \mathrm{~m}$ for both) and $\beta$ (about $0.01-0.1$ for both). The two data sets differ in the range of offshore wave conditions - in the original data set $H_{0}$ and $T_{\mathrm{p}}$ range over 0.4-4.1 (m) and 3.7$17(\mathrm{~s})$, while in the new data set the ranges are 0.6-6.4 (m) and 8.1-16.4 (s).

The dissipative beaches of the original data set (Fig. 2d, h) are Terschelling (Netherlands) and Agate (USA), and for the new data set on Ngarunui in New Zealand (although, during the experiment, the beach also experienced intermediate conditions). The purely intermediate beaches for the original and new data set are Scripps (USA) and Truc Vert (France). Some beaches from the original data set (USA) represent both intermediate and reflective conditions: Duck 94, Gleneden, Sandy Duck, Delilah and Duck 82. San Onofre for the original and Tairua (New Zealand) for new data set are reflective.

\section{Methodology}

The large amount of data available (636 field swash records), including multidimensional variables, supports the feasibility of a ML approach. The data cover a wide range of environmental conditions (including extreme storms) and beach types, ensuring the applicability of our results to sandy beaches spreading from dissipative to reflective. We now outline the methods of the study. In Sect. 3.1, we present the supervised ML approach. In Sect. 3.2 we present the data preprocessing technique used to decide what data are shown to the ML algorithm. In Sect. 3.3 we discuss the techniques used to test the results from the ML algorithm against the testing data.

\subsection{Genetic programming}

GP is a population-based machine learning approach based on evolutionary computation (Koza, 1992). The process of genetic programming can generally be divided into four steps: (1) an initial population of solutions for the problem is produced. For regression tasks such as developing a predictor for swash, the initial population of candidate solutions is in the form of equations (encoded as a tree or graph with a predefined mix of variables, operators and coefficients; Fig. 3). 

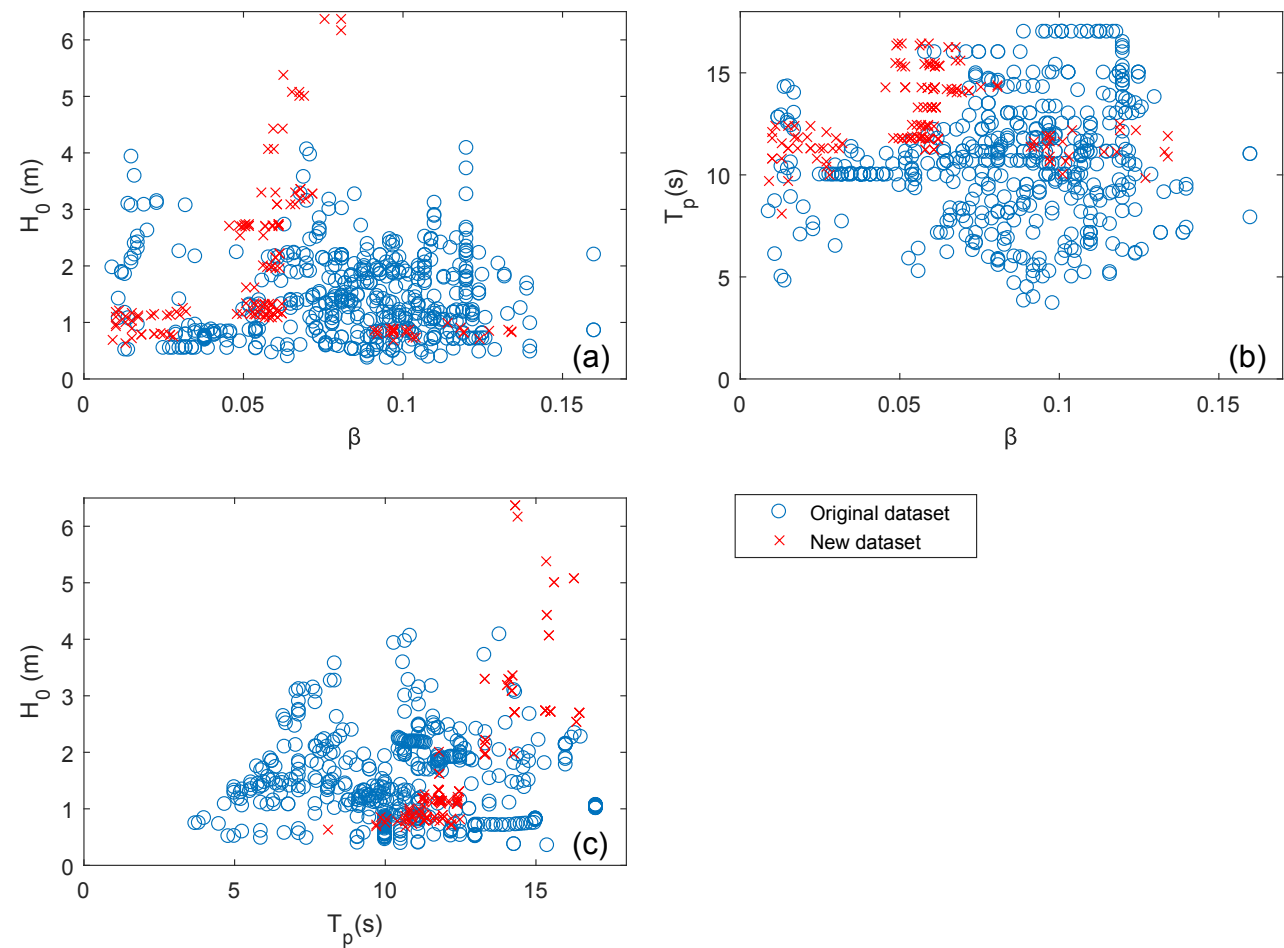

Original dataset

$\times \quad$ New dataset

Figure 1. Environmental forcing conditions (blue circles: original data set, red crosses: new data set): (a) significant wave height versus beach slope, (b) wave peak period versus beach slope, (c) significant wave height versus wave peak period.

Table 1. Summary of wave and beach parameters for the original and the new data sets, beach name and type (following the classification of Short (1999) based on Iribarren number (D stands for dissipative, I for intermediate and R for reflective); the last two rows indicate the range of parameters of the entire two data sets. Each experiment is associated with the citation where the measurements have been originally presented. If no reference is given, the citation is Stockdon et al (2006).

\begin{tabular}{|c|c|c|c|c|c|c|c|c|}
\hline Experiment & Data set (data points) & $H_{\mathrm{S}}(\mathrm{m})$ & $T_{\mathrm{p}}(\mathrm{s})$ & $\beta$ & $\xi_{0}$ & Beach type & $S_{\text {Tot }}$ & $S_{\text {Ig }}$ \\
\hline $\begin{array}{l}\text { Duck } 94 \\
\text { (Holland and Holman, 1996) }\end{array}$ & Original (52) & $0.7-4.1$ & $3.8-14.8$ & $0.06-0.1$ & $0.33-1.43$ & $\mathrm{I}, \mathrm{R}$ & $0.8-2.9$ & $0.5-2.2$ \\
\hline Gleneden & Original (42) & $1.8-2.2$ & $10.5-16$ & $0.03-0.11$ & $0.26-1.2$ & $\mathrm{I}, \mathrm{R}$ & $1.1-2.3$ & $0.9-1.9$ \\
\hline Sandy Duck & Original (95) & $0.4-3.6$ & $3.7-15.4$ & $0.05-0.14$ & $0.34-3.22$ & $\mathrm{I}, \mathrm{R}$ & $0.7-2.3$ & $0.3-1.8$ \\
\hline San Onofre & Original (59) & $0.5-1.1$ & $13-17$ & $0.07-0.13$ & $1.6-2.62$ & $\mathrm{R}$ & $0.9-2.6$ & $0.5-1.8$ \\
\hline $\begin{array}{l}\text { Terschelling } \\
\text { (Ruessink et al., 1998) }\end{array}$ & Original (14) & $0.5-3.9$ & $4.8-10.6$ & $0.01-0.03$ & $0.07-0.22$ & $\mathrm{D}$ & $0.2-1$ & $0.2-0.9$ \\
\hline $\begin{array}{l}\text { Scripps Beach } \\
\text { (Holland et al., 1995) }\end{array}$ & Original (41) & $0.5-0.8$ & $10-10$ & $0.03-0.06$ & $0.4-0.92$ & I & $0.3-0.7$ & $0.3-0.7$ \\
\hline $\begin{array}{l}\text { Delilah } \\
\text { (Holland and Holman, 1993) }\end{array}$ & Original (138) & $0.5-2.5$ & $4.7-14.8$ & $0.03-0.14$ & $0.44-1.70$ & $\mathrm{I}, \mathrm{R}$ & $0.7-3.3$ & $0.4-1.7$ \\
\hline $\begin{array}{l}\text { Duck } 82 \\
\text { (Holman, 1986) }\end{array}$ & Original (36) & $0.5-4.1$ & $6.3-16.5$ & $0.09-0.16$ & $0.68-2.38$ & $\mathrm{I}, \mathrm{R}$ & $0.7-3$ & $0.4-2.4$ \\
\hline $\begin{array}{l}\text { Agate } \\
\text { (Ruggiero et al., 2001) }\end{array}$ & Original (14) & $1.8-3.1$ & $7.1-14.3$ & $0.01-0.02$ & $0.1-0.19$ & $\mathrm{D}$ & $0.7-1.5$ & $0.7-1.5$ \\
\hline $\begin{array}{l}\text { Ngarunui } \\
\text { (Guedes et al., 2013) }\end{array}$ & New (32) & $0.6-1.26$ & $8.1-12.4$ & $0.01-0.03$ & $0.13-0.42$ & $\mathrm{D}$ & $0.24-0.9$ & $0.24-0.9$ \\
\hline $\begin{array}{l}\text { Tairua } \\
\text { (Guedes et al., 2011) }\end{array}$ & New (25) & $0.7-1$ & $9.9-12.5$ & $0.09-0.13$ & $1.4-2.25$ & $\mathrm{R}$ & $1.2-2.2$ & $0.6-0.95$ \\
\hline $\begin{array}{l}\text { Truc Vert } \\
\text { (Senechal et al., 2011). }\end{array}$ & New (88) & $1.1-6.4$ & $11.2-16.4$ & $0.05-0.08$ & $0.49-0.9$ & I & $0.81-2.5$ & $0.63-2.37$ \\
\hline All beaches & $\begin{array}{l}\text { Entire original (491) } \\
\text { (Stockdon et al., 2006) }\end{array}$ & $0.4-4.1$ & $3.7-17$ & $0.01-0.16$ & $0.07-3.22$ & $\mathrm{D}, \mathrm{I}, \mathrm{R}$ & $0.2-3.3$ & $0.2-2.4$ \\
\hline All beaches & Entire new (145) & $0.6-6.4$ & $8.1-16.4$ & $0.01-0.13$ & $0.13-2.25$ & $\mathrm{D}, \mathrm{I}, \mathrm{R}$ & $0.24-2.5$ & $0.24-2.37$ \\
\hline
\end{tabular}



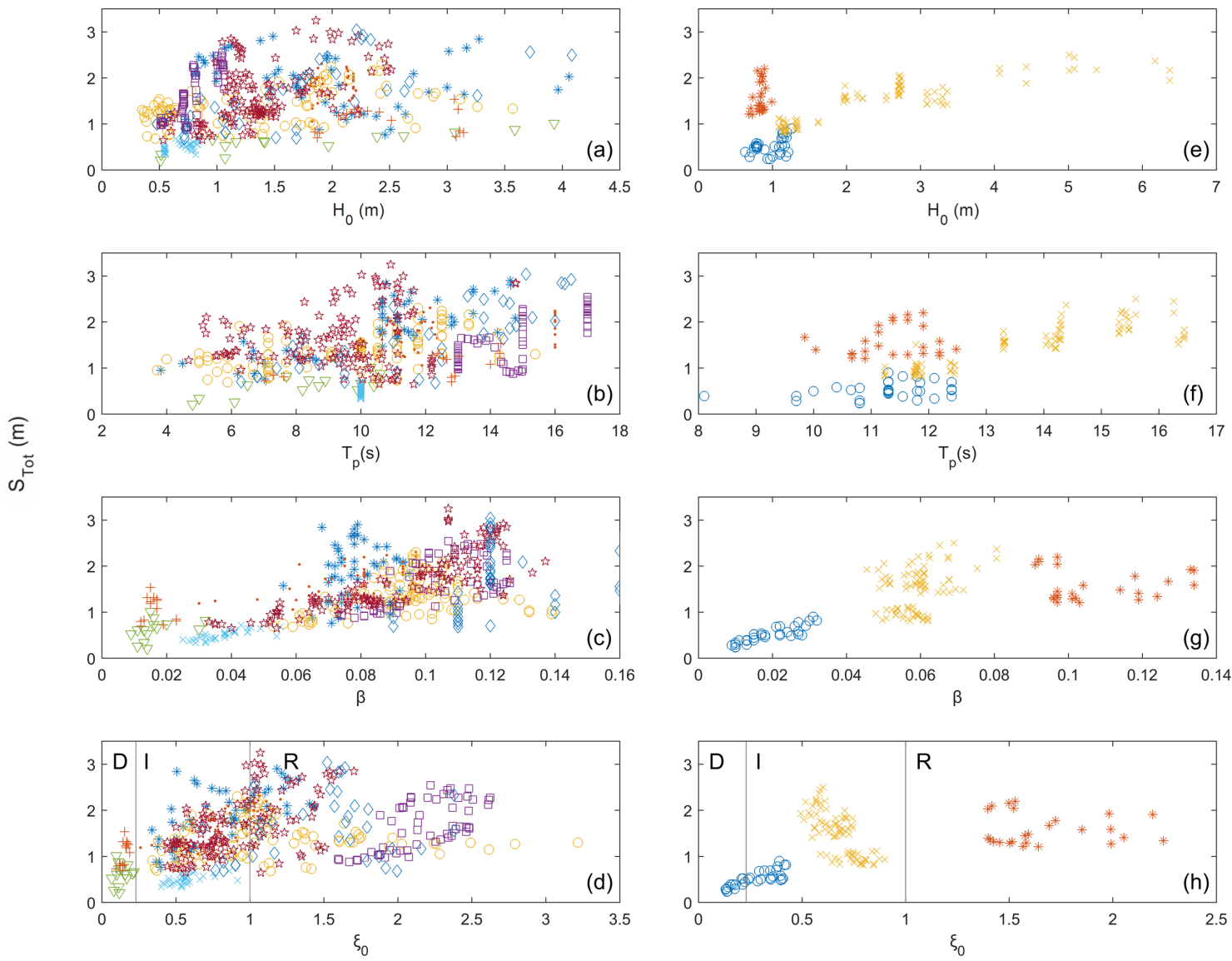

\begin{tabular}{|clcl|}
\hline$*$ Duck 94 & & \\
& Gleneden & $\times$ & Scripps Beach \\
& Sandy Duck & $\star$ & Delilah \\
$\square$ & San Onofre & $\diamond$ & Duck 82 \\
$\nabla$ & Terschelling & + & Agate \\
\hline
\end{tabular}

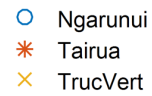

Figure 2. Total swash dependence on the environmental variables of the original $(\mathbf{a}, \mathbf{b}, \mathbf{c}, \mathbf{d})$ and new $(\mathbf{e}, \mathbf{f}, \mathbf{g}, \mathbf{h})$ data sets. The variables displayed are significant wave height $(\mathbf{a}, \mathbf{e})$, wave peak period $(\mathbf{b}, \mathbf{f})$, beach slope $(\mathbf{c}, \mathbf{g})$ and Iribarren number $(\mathbf{d}, \mathbf{h})$. Beaches are considered dissipative (D) for values of $\xi_{0}<0.23$, reflective (R) for $\xi_{0}>1$ and intermediate (I) between the two (Short, 1999).

For step (2) of the routine the solutions are all compared to the training data to determine "fitness" using a predefined error metrics; (3) the best solutions that minimize the error are proposed and the worst solutions are discarded; (4) new solutions are created through "evolutionary" rules (crossover via reproduction and mutation) and are added to the population of retained solutions. Steps 2 to 4 are repeated until the algorithm is stopped. The search is stopped after the GP evaluated $10^{11}$ formulas because the solutions stabilized and no significant improvement in formula performance was found.

At the end of a routine, when the solutions have stabilized, a final population of solutions exist. A range of final solutions is given by the algorithm - more mathematically complex solutions (with more variables, operators, and coefficients) that minimize error are given alongside more simple, parsimonious solutions with higher errors. These solutions exist along a Pareto front that balances decreases in error with increasing solution complexity. Given a range of solutions with different error and complexity, we do not know of a perfect method for a user to determine the single best solution from the suite of final solutions - a user must decide on the solution according to different criteria: minimization of the error, computational time and physical meaning. In our work we adopted the criteria of minimization of the error while making sure the formulas could be interpreted physically. A compromise between error reduction (more complex predictors) and ability of the predictors to generalize (predictive power on new data) should be found during the selection of a predictor.

All genetic programming in this study is performed using the software Eureqa developed by Schmidt and Lipson $(2009,2013)$ which has successfully been used for a 


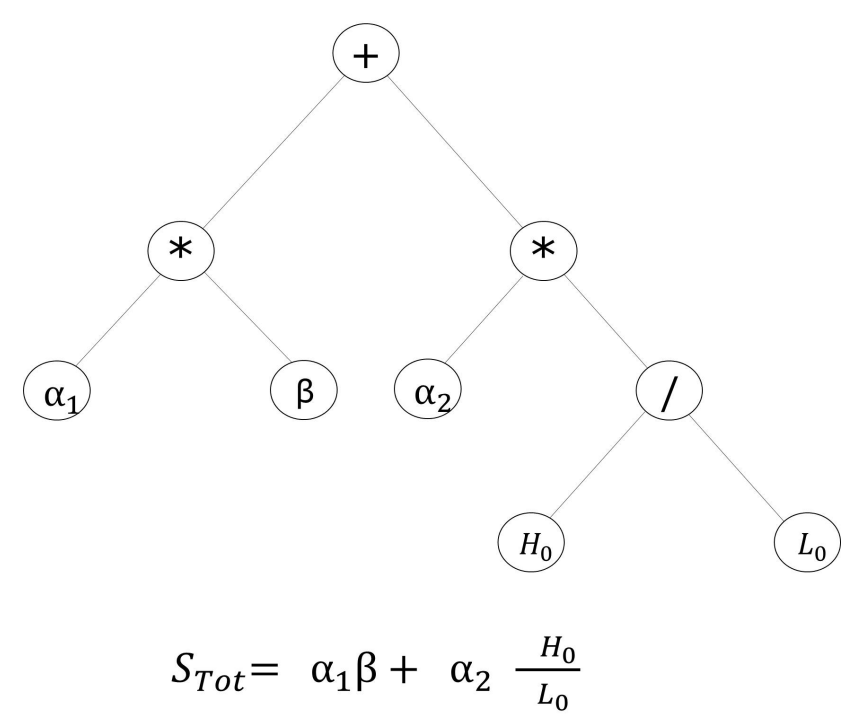

Figure 3. Schematics of the GP structure and principle of operation for an example of the simple total swash predictor. $\alpha_{1}$ and $\alpha_{2}$ are the coefficients; $\beta, H_{0}$ and $L_{0}$ the variables; and,$+{ }^{*}$ and / the mathematical operators.

range of coastal problems (e.g. Goldstein et al., 2013; Tinoco et al., 2015). We search for predictors of total and infragravity swash elevation - ultimately searching for the best equation that satisfies $S_{\text {Tot } / \mathrm{Ig}}=f\left(H_{0}, L_{0}, \beta, T_{\mathrm{p}}\right)$. Note also that we perform some experiments by searching for total and infragravity swash as a function of composite variables like wave steepness, wave power $\left(P_{\mathrm{w}}\right)$ and the Iribarren number. However, the predictors did not show improvement - also keep in mind that the GP can autonomously find these interrelationships between the basic parameters themselves, leading to the appearance of these composite variables in each optimization experiment. In addition to physical parameters, constants are included in the research and the mathematical operations allowed for the GP are addition $(+)$, subtraction (-), multiplication $(\cdot)$, division $(/)$, exponential ( () and square root $(\sqrt{ })$. Predictors developed on the training subset are assessed on the validation subset, using an error metric (also known as fitness function). From the available metrics we selected the mean squared error (MSE):

$\operatorname{MSE}=\frac{1}{N} \sum_{i=1}^{N}\left(y_{i}-f(x)_{i}\right)^{2}$,

where $N$ is the number of samples, $y_{i}$ is the measured value, and $f(x)_{i}$ is the value predicted by GP as a function of $x$.

All selected formulas from the genetic programming routine are further optimized. First, the formulas are rearranged algebraically to ease interpretation by the user. Second, two coefficients of each selected formula are further optimized using a gradient descent algorithm in an iterative process.

\subsection{Training, validation and testing}

In order to obtain generalizable predictors, it is necessary to train, validate and test any ML routine on distinct and nonoverlapping subsets of data (e.g. Domingos, 2012). There is no universal, optimal method for selecting enough data to explain variability of the data set while still retaining the most data to use for testing. Recent work by Galelli et al. (2014) highlights that, even with the numerous input variable selection methods that have been proposed, there is no single best method for all the typologies of environmental data sets and for all environmental models.

We adopt the maximum dissimilarity algorithm (MDA) as a selection routine (e.g. Camus et al., 2011), which has already been successfully tested in other works of predictors developed by GP for physical problems (e.g. Goldstein and Coco, 2014). The MDA is a routine for the selection of the most dissimilar points in a given data set. Each data point is a vector composed of all the variables of our data set $\left(\eta, S_{\text {Tot }}\right.$, $\left.S_{\mathrm{Ig}}, S_{\mathrm{in}}, H_{0}, L_{0}, \beta, T_{\mathrm{p}}, \xi_{0}, P_{\mathrm{w}}, R\right)$, where each variable is normalized between 0 and 1 . At each iteration $(i=1 \ldots n)$, the MDA finds the most different data point from the data selected in all previous iterations. Consequently the MDA selects a diverse set of data from the original 491 data points used by Stockdon et al. (2006). The operator must set the number of data points selected - we apply the MDA to 150 data points ( $\sim 30 \%$ of the original data set). We also run the analysis using a subset of variables (not including the variables representing swash elevations) but no significant loss in prediction power of the algorithms developed by the machine learning algorithm was observed. The data selected by the MDA are used as the training subset and we use the remaining data ( $\sim 70 \%$ of the original data set, not selected) as a validation subset.

The predictors developed by the GP using this training data are tested using the new data set from Guedes et al. (2011, 2013), and Senechal et al. (2011). This new data set is completely independent from the training and unknown to the GP algorithm, providing a test in the ability of the GP parameterization to generalize, even beyond the range of the testing and validation data (Fig. 1). The performance of our predictors using the testing data is compared to the Stockdon et al. (2006) predictors using the error metrics in Sect. 3.3.

\subsection{Error evaluation}

We use three different error metrics for the testing phase and for comparing our predictor with known predictors in the literature: the mean square error as defined in Eq. (8), the root mean square error

$\mathrm{RMSE}=\sqrt{\frac{1}{N} \sum_{i=1}^{N}\left(y_{i}-f(x)_{i}\right)^{2}}$,

and the maximum absolute error

$\operatorname{MaxAE}=\max _{i=1 \ldots N}\left(y_{i}-f(x)_{i}\right)$, 


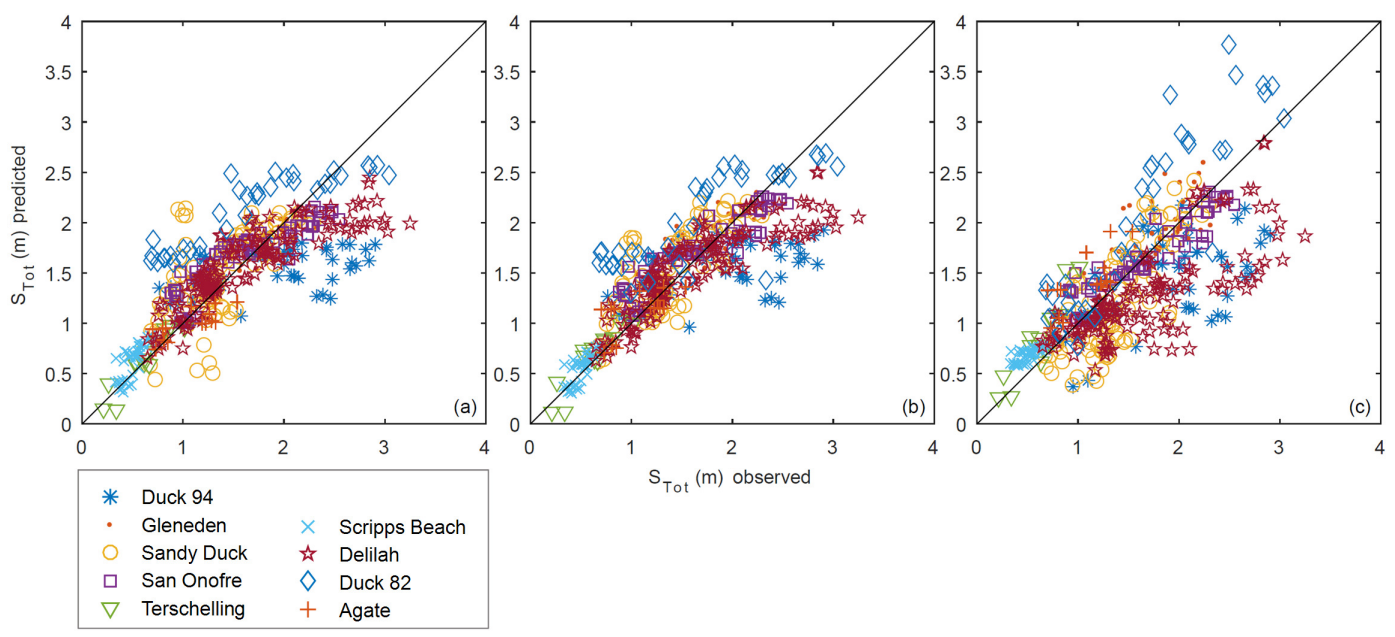

Figure 4. Observed versus predicted $S_{\text {Tot }}$ using (a) GP Eq. (11), (b) GP Eq. (12) and (c) Stockdon et al. (2006) Eq. (5) for the original data set (Stockdon et al., 2006). This is not a test of any predictor, only a consistency check - all data were shown to the GP algorithm and used to generate the linear regression in (c).

where $N$ is the number of samples, $y_{i}$ is the measured value, and $f(x)_{i}$ is the value predicted by the GP as a function of $x$.

\section{Results}

\subsection{Results of GP experiments}

After $\sim 10^{11}$ formulas were evaluated, the solutions from the GP algorithm for both $S_{\text {Tot }}$ and $S_{\mathrm{Ig}}$ follow a Pareto front in which the error decreases (compared with the validation subset) as the size (or complexity) of the formula increases. Generally, extremely complicated predictors fit the training and validation data sets better than simpler predictors but they may lose generalization power when tested on a separate testing data set (overfitting). In other words a predictor with overfitting could represent the noise in the training and validation subsets instead of defining a general predictive rule (Dietterich, 1995) and therefore it will result in smaller training errors but in higher testing errors. Several viable techniques exist for selecting the best solution to avoid overfitting, all meant to balance the fact that simpler solutions (the minimum description length) might risk losing more accurate information contained in more complex models (e.g. O'Neill et al., 2010). Picking a solution is a subjective task and relies on specific domain knowledge on the part of the user. Here we focus on predictors with clear physical plausibility (avoiding predictors with physical nonsense such as increase of $S_{\text {Tot }}$ as $H_{0}$ decreases) and avoid predictors that are difficult to interpret (e.g. extremely non-linear relationships, possibly a result of overfitting the training data set). We also focus on two predictors for both the $S_{\text {Tot }}$ and $S_{\mathrm{Ig}}$, evaluating a simpler and more complex predictor to determine whether the more complex expression warrants use when generalized to the testing data set.

\subsection{Total swash}

Following the principle of error reduction and physical interpretability of the results, from the pool of candidate solutions available from the GP experiments, we finally select two formulas for $S_{\text {Tot }}$, one simpler (Eq. 11) and one more elaborate (Eq. 12).

$$
\begin{aligned}
& S_{\text {Tot }}=12.314 \beta+0.087 T_{p}-0.047 \frac{T_{\mathrm{p}}}{H_{0}}, \\
& S_{\text {Tot }}=146.737 \beta^{2}+\frac{T_{\mathrm{p}} H_{0}^{3}}{5.800+10.595 H_{0}^{3}}-4397.838 \beta^{4}
\end{aligned}
$$

Note that the coefficients of both Eqs. (11) and (12) are dimensional. Equation (11) represents the best solution in terms of error reduction while maintaining a physical interpretability. It also stands out for its simplicity and only weak non-linearity - it looks similar to a multiple linear regression. In Eq. (12) the first and the third term depend exclusively on $\beta$, while the second term includes the contribution of the incident waves. The total swash in both GP predictors is related to the wave peak period (instead of wavelength) different from previous formulations (e.g. Stockdon et al., 2006; Holman and Sallenger, 1985). Recently Poate et al. (2016) also used the wave peak period in their run-up predictor for gravel beaches. The use of the peak period instead of the wavelength has no influence on the physics of the predictor, but could allow the users a more direct utilization of the formula.

Figure 4 displays a comparison of performance of swash predictors obtained through the ML approach (Fig. 4a, b) and Stockdon et al. (2006) (Fig. 4c) on the training and validation 


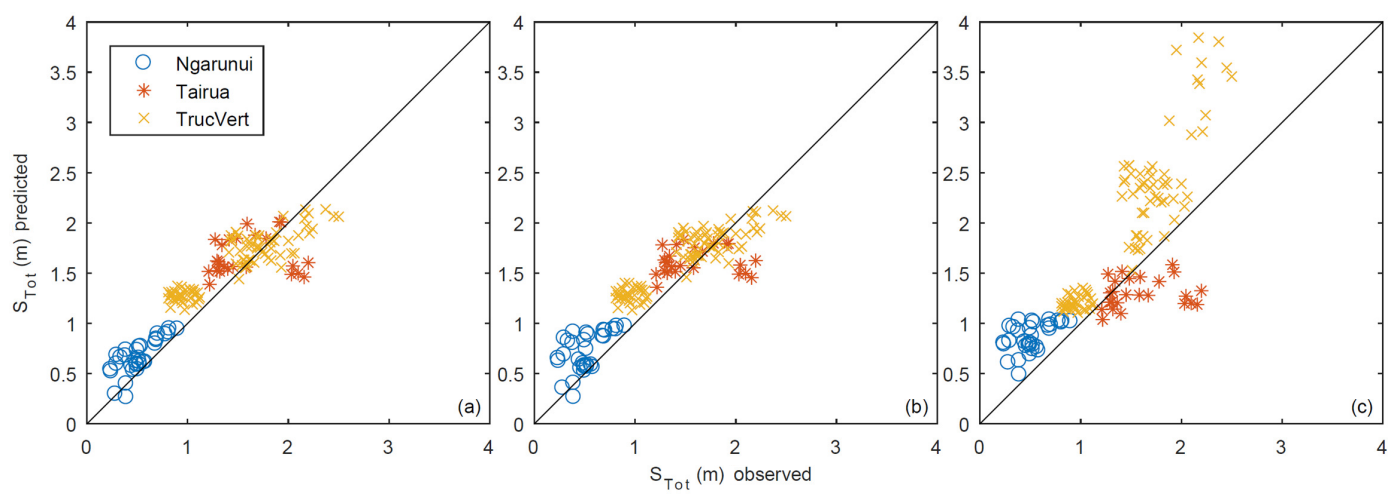

Figure 5. Observed versus predicted $S_{\text {Tot }}$ with the new independent data set. (a) GP Eq. (11), (b) GP Eq. (12) and (c) Stockdon et al. (2006) - Eq. (5) in this paper.

data set. This does not constitute a test of the predictors, only a consistency check to see that the predictors are modelling the training and validation data appropriately. Overall Eq. (5) shows a higher scatter in the whole original data set (details on the errors can be found in Table 2 and Sect. 4.4). It is not clear why all formulas do not successfully fit the data sets Duck 82 and Delilah (especially for $S_{\text {Tot }}>2 \mathrm{~m}$ ). The Stockdon et al. (2006) predictor shows scatter at larger total swash, while the GP predictors shows slight underfitting of swash elevation during large events. Stockdon et al. (2006), Eqs. (5), (6) and (7) in this contribution, mostly underpredict the data with exclusion of the Duck 82 data set, which is largely overpredicted for high values of the swash excursion. Both GP predictors more accurately fit data from dissipative beaches (Agate and Terschelling) compared with the Stockdon et al. (2006) formula.

Figure 5 shows the observed versus the predicted $S_{\text {Tot }}-$ both GP models and Stockdon et al. (2006) - for the new, testing data set. Note that swash values $(0-2.5 \mathrm{~m})$ are lower than the maxima observed in the original data set, but these values represent absolutely new, out-of-sample prediction for all equations. Overall the Stockdon et al. (2006) formula has higher scatter than both GP predictors (Fig. 5) and considerably overestimates swash measurement of Truc Vert (intermediate beach under extreme highly energetic wave storm) and Ngarunui (dissipative beach under mild wave conditions) but underestimates the observations at the reflective beach of Tairua. Equations (11) and (12) from the GP routine perform similarly (Fig. 5a, b).

\subsection{Infragravity swash}

The two formulas selected for describing $S_{\text {Ig }}$ are Eq. (13) and the more complex Eq. (14):

$S_{\mathrm{Ig}}=10 \beta+\frac{\beta}{\beta-0.306}+\frac{H_{0}-0.456}{0.447+136.411\left(\frac{H_{0}}{L_{0}}\right)}$

$$
\begin{aligned}
S_{\text {Ig }} & =\frac{\beta}{0.028+\beta}+\frac{(-1)}{2412.255 \beta-5.521 \beta L_{0}} \\
& +\frac{H_{0}-0.711}{0.465+173.470\left(\frac{H_{0}}{L_{0}}\right)} .
\end{aligned}
$$

As in the case of $S_{\text {Tot }}$, the coefficients of Eqs. (13) and (14) for $S_{\mathrm{Ig}}$ are dimensional. The reader should also note that both formulas depend on the beach slope in contrast with Ruessink et al. (1998) and Stockdon et al. (2006), Eq. (7) in this paper, but in agreement with other slope inclusive predictors (Ruggiero et al., 2001, 2004). Equation (14) represents the best solution in terms of error reduction while maintaining physical meaning and Eq. (13) is a simpler predictor where the contribution of beach slope and waves to infragravity swash remains separate. Both Eqs. (13) and (14) have the same non-linear term $\frac{H_{0}-0.456}{0.447+136.411\left(\frac{H_{0}}{L_{0}}\right)}$, with slight difference in the coefficients that describe the incoming waves. The threshold that flips this term from negative to positive is related to wave height and is probably an indication that for small waves the infragravity component is extremely limited (this terms needs to be negative to compensate for other terms that only depend on beach slope and provide a constant contribution). The ML predictor not only suggests that the beach slope is important when predicting infragravity swash, but also indicates a non-linear interaction between waves and beach morphology through the wavelength (second term of Eq. 14).

Figure 6 displays a consistency check, highlighting the performance of swash predictors obtained through a ML approach (Fig. 6a, b) and Stockdon et al. (2006) (Fig. 6c), on the training and validation data set. It is not clear why all formulas provide less precise predictions with data from Duck 84 and Duck 82 but we note that these two experiments focused on intermediate to reflective conditions with relatively large wave conditions (Table 1). Generally the three formulas seem to perform similarly. Some differences are found in dissipative settings (i.e. Agate and Terschelling) - predictions 
Table 2. Results of error metrics for both total and infragravity swash, calculated for the GP predictors and Stockdon et al. (2006) on both original and new data sets. The results calculated with the original data set (in italics) do not represent a test of any predictor, only a consistency check - all original data were shown to the GP algorithm and used by Stockdon et al. (2006).

\begin{tabular}{|c|c|c|c|c|}
\hline Target & Formula (methodology) & Error metrics & $\begin{array}{l}\text { New data set } \\
\text { (Independent) }\end{array}$ & $\begin{array}{c}\text { Original data set, Stockdon } \\
\text { et al. (2006) }\end{array}$ \\
\hline \multirow[t]{9}{*}{ Total swash } & \multirow[t]{3}{*}{ Eq. (11) (GP) } & $\operatorname{MSE}\left(\mathrm{m}^{2}\right)$ & 0.074 & 0.144 \\
\hline & & $\operatorname{RMSE}(\mathrm{m})$ & 0.272 & 0.380 \\
\hline & & $\operatorname{MaxAE}(\mathrm{m})$ & 0.695 & 1.257 \\
\hline & \multirow[t]{3}{*}{ Eq. (12) (GP) } & $\operatorname{MSE}\left(\mathrm{m}^{2}\right)$ & 0.083 & 0.126 \\
\hline & & $\operatorname{RMSE}(\mathrm{m})$ & 0.288 & 0.355 \\
\hline & & $\operatorname{MaxAE}(\mathrm{m})$ & 0.702 & 1.258 \\
\hline & \multirow[t]{3}{*}{ Eq. (5) Stockdon et al. (2006) } & $\operatorname{MSE}\left(\mathrm{m}^{2}\right)$ & 0.325 & 0.214 \\
\hline & & $\operatorname{RMSE}(\mathrm{m})$ & 0.570 & 0.462 \\
\hline & & $\operatorname{MaxAE}(\mathrm{m})$ & 1.771 & 1.399 \\
\hline \multirow[t]{9}{*}{ Infragravity } & \multirow[t]{3}{*}{ Eq. (13) (GP) } & $\operatorname{MSE}\left(\mathrm{m}^{2}\right)$ & 0.071 & 0.047 \\
\hline & & $\operatorname{RMSE}(\mathrm{m})$ & 0.267 & 0.217 \\
\hline & & $\operatorname{MaxAE}(\mathrm{m})$ & 0.679 & 1.019 \\
\hline & \multirow[t]{3}{*}{ Eq. (14) (GP) } & $\operatorname{MSE}\left(\mathrm{m}^{2}\right)$ & 0.047 & 0.053 \\
\hline & & $\operatorname{RMSE}(\mathrm{m})$ & 0.216 & 0.231 \\
\hline & & $\operatorname{MaxAE}(\mathrm{m})$ & 0.587 & 1.025 \\
\hline & \multirow[t]{3}{*}{ Eq. (7) Stockdon et al. (2006) } & $\operatorname{MSE}\left(\mathrm{m}^{2}\right)$ & 0.111 & 0.068 \\
\hline & & $\operatorname{RMSE}(\mathrm{m})$ & 0.334 & 0.261 \\
\hline & & $\operatorname{MaxAE}(\mathrm{m})$ & 0.988 & 1.056 \\
\hline
\end{tabular}

by Stockdon et al. (2006) tend to overestimate $S_{\text {Ig }}$ compared to the GP predictors.

The same difficulty in predicting swash excursion on a dissipative beach is observed on Ngarunui (Fig. 7), even though this experiment was performed under mild wave conditions ( $H_{0} \sim 0.6-1.26(\mathrm{~m})$ and $T_{\mathrm{p}} \sim 8.1-12.4$ (s), Table 1$)$ compared to the experiments at Agate and Terschelling. Note that dissipative beaches are ones for which the infragravity motion has greater importance. Also, Truc Vert presents dissipative conditions in the swash zone, while the surf zone is intermediate ( $\xi_{0}$ up to 0.87 as reported by Senechal et al., 2011). For this experiment Eqs. (13) and (7) (Fig. 7a, c) overestimate $S_{\text {Ig }}$, while Eq. (14) has better performance for the dissipative beach Ngarunui, suggesting that it could be the most appropriate for $S_{\text {Ig }}$ predictions.

Table 2 summarizes the results of the errors calculated through three error metrics (Sect. 3.3) of the two GP predictors and the Stockdon et al. (2006) formulas on both original and independent data sets.

Overall the GP predictors perform better than the Stockdon et al. (2006) formulation for all the error metrics considered and for the new testing data sets (for both $S_{\text {Tot }}$ and $S_{\mathrm{Ig}}$ ). While for $S_{\text {Tot }}$ the predictor of smaller size performs better than the more complex predictor, for $S_{\text {Ig }}$ the errors decrease with increasing GP predictor size (Eqs. 13 to 14) when tested on the new data set. Equation (11) has the smallest RMSE (0.272 m), MSE (0.074 $\left.\mathrm{m}^{2}\right)$ and $\operatorname{MaxAE}(0.695 \mathrm{~m})$ of the $S_{\text {Tot }}$ formulas, evaluated on the new data set, while the predictor from Stockdon et al. (2006) - Eq. (5) of this paper - has the highest RMSE $(0.570 \mathrm{~m}), \operatorname{MSE}\left(0.325 \mathrm{~m}^{2}\right)$ and MaxAE (1.771 m). Equation (14) performs slightly better than Eq. (13) in predicting $S_{\text {Ig }}$ evaluated on the new data set, while the difference is larger when compared to the predictor from Stockdon et al. (2006) - Eq. (7) of this paper.

\section{Discussion}

In this work we use data compiled by Stockdon et al. (2006) to build new predictors by the use of GP for both total and infragravity swash elevations. We then test the generalizability of these new predictors using new data (including some extreme conditions). This is different from many previous applications of ML in coastal settings in two ways: first, we are testing the ML-derived predictor on data that are collected from a different setting (compared to the training data) - three beaches not included in the training data. Second, the testing data includes events that are outside the data range of the training data. We are extrapolating the ML-derived predictor as a test of its generalizability. We do not assume a single criteria for the selection of the best predictors, but we find a compromise between error reduction (on the testing data set) and the physical interpretability of the results.

Results demonstrate that the GP predictors proposed in this work perform better than existing formulas and that ML can identify non-linear relationships between the variables of this problem. Specifically, Eq. (14) introduces the dependence of $S_{\text {Ig }}$ on the beach slope, but also its non-linear re- 


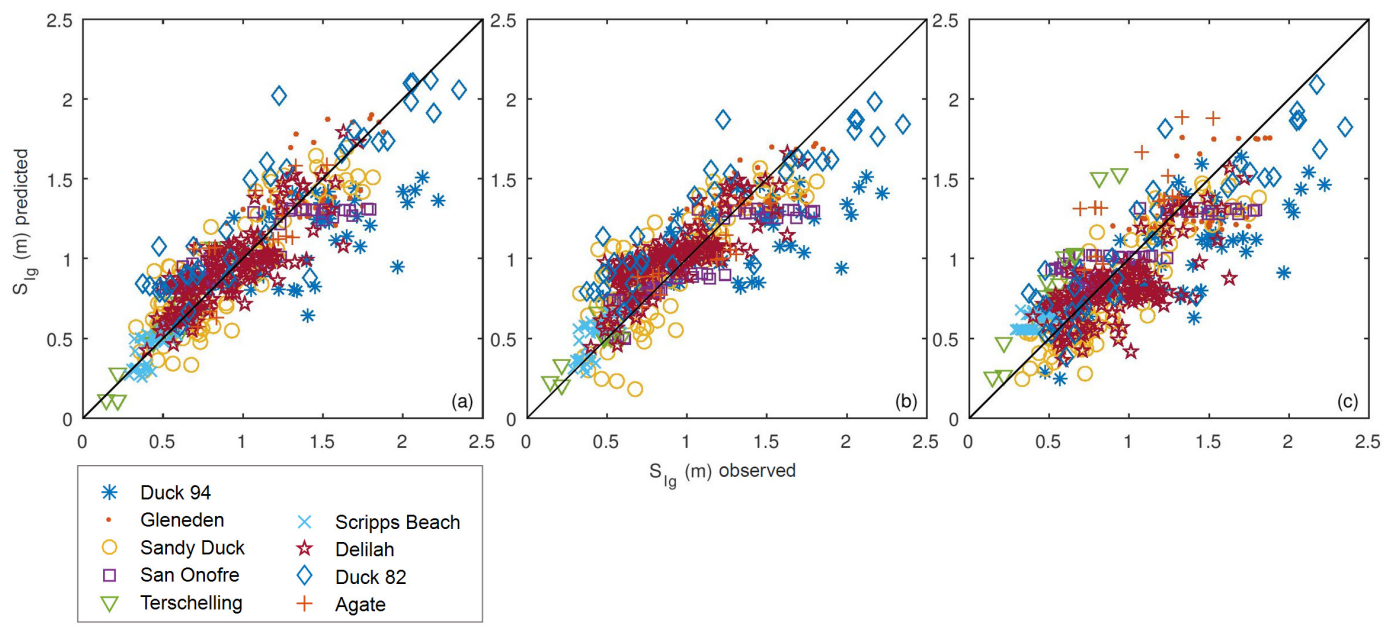

Figure 6. Observed versus predicted $S_{\text {Ig }}$ by (a) GP Eq. (13), (b) GP Eq. (14) and (c) Stockdon et al. (2006) Eq. (7) on the original data set (Stockdon et al., 2006). This is not a test of any predictor, only a consistency check - all data were shown to the GP algorithm and are the same data used to generate the linear regression in (c).
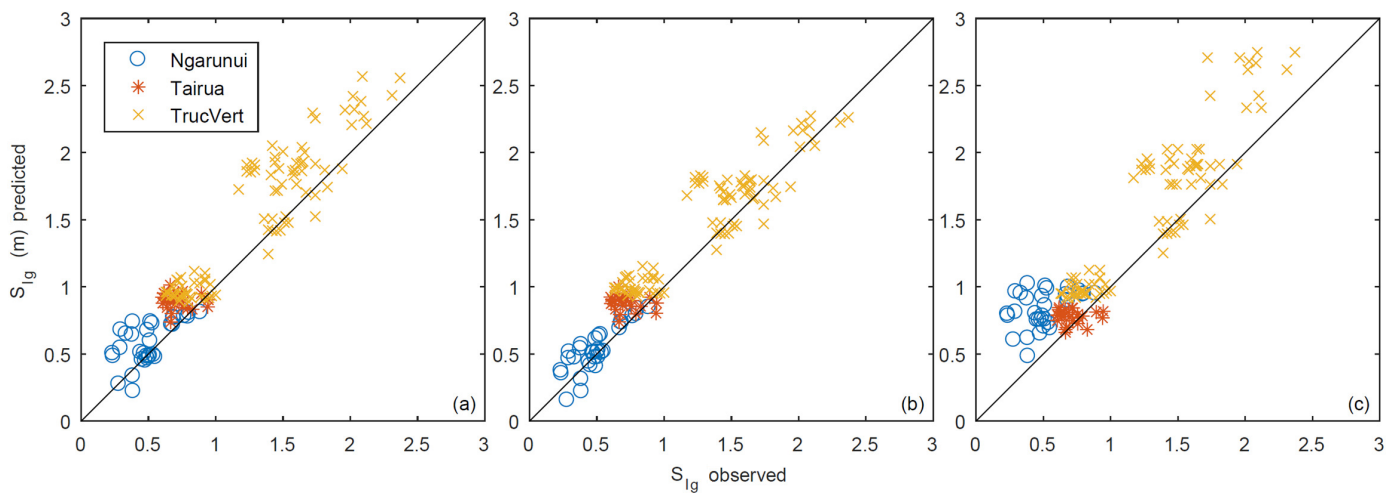

Figure 7. Observed versus predicted $S_{\text {Ig }}$ using (a) GP Eq. (13), (b) GP Eq. (14) and (c) Stockdon et al. (2006) Eq. (7) on the new independent data set.

lationship with the wavelength. Furthermore, solutions for $S_{\text {Ig }}$ found by the GP algorithm with the smaller size (not shown) show a simple linear dependence on $H_{0}$ with a constant (identical to early formulation of wave run-up, e.g. of Guza and Thornton, 1982). More complex predictors add a dependence on $L_{0}, \sqrt{H_{0} L_{0}}$ (similar to Eq. (7) of this paper from Stockdon et al., 2006) and $\frac{H_{0}}{L_{0}}$.

The GP algorithm found solutions for $S_{\text {Ig }}$ that include the beach slope $(\beta)$, a variable that is never excluded from predictors of further increasing size. Because the candidate solutions resulted from GP experiments follow a Pareto front distribution in which the increase in fitting (smaller MSE) grows as the size of the formula rises, the continuous inclusion of $\beta$ for more complex predictors implies that including $\beta$ in $S_{\mathrm{Ig}}$ formulation reduces prediction error. The improvement of classic empirical techniques, by innovation in datadriven methodologies, has already been discussed (e.g. the case of depth-averaged velocities over model vegetation by
Tinoco et al., 2015). Experiments based on GP also highlighted a way to focus on and add dependencies in predictors describing coastal processes (e.g. grain size in the case of prediction of ripple wavelength by Goldstein et al., 2013). The predictors proposed in this work perform well on a wide range on environmental conditions, including, as defined by Nicolae et al. (2016), the highest stormy condition data set (Truc Vert beach) recorded in the field and available in the literature. Furthermore the work here demonstrates that MLderived results, when physically plausible, may be generalizable beyond the limits of the training data, extrapolating to a novel, out-of-sample data set.

Looking at the limitation of the proposed models, the variables taken into account $\left(H_{0}, T_{p}, L_{0}, \beta\right)$ are easily accessible but also oversimplify the processes that affect swash. For instance, we do not include the influence of the wavedirectional spread (Guza and Feddersen, 2012), the crossshore wind component and the tidal range (Vousdoukas et al., 
2012). However, in order to include these and other aspects (e.g. role of underwater vegetation, nearshore bathymetry) it is necessary to perform more field experiments that record swash, run-up and other relevant variables. An additional limitation is that the swash formulas obtained in this study approach a non-zero value as wave height approaches zero. While this is physically incorrect, the data used in the analysis do not include the limited condition of "no waves - no swash". Consequently, even if the GP formulas obtained do not correctly predict the limit condition corresponding to a no wave scenario, the prediction for both data sets has smaller errors compared to commonly used formulas. Generally the results from the machine learning technique are strictly related to the range of the training and validation data sets (original data set in Fig. 1). This work demonstrated that the applicability of the predictors can sometimes be used beyond the range of the testing data set (new data set in Fig. 1). However it is unknown how predictors will perform in settings beyond those in the present work - future tests on new field data are therefore recommended. Furthermore, parameterizations always work better when free parameters are optimized to a given site by using existing data and should be considered when proposing universal parameterizations.

Our results contribute to the discussion on the role of beach slope on the prediction of the infragravity component of swash. The GP algorithm found an $S_{\text {Ig }}$ dependence on beach slope and increasingly more complicated formulas (i.e. more precise predictions) found by the GP all include beach slope as one of the predictive variables. This result is in line with studies such as Ruggiero et al. $(2001,2004)$ and in contrast with Stockdon et al. (2006), Senechal et al. (2011) and Ruessink et al. (1998). Although difficult to quantify and extremely simplified (this parameter together with sediment diameter should integrate the effect of the entire cross-shore profile), our results suggest that some parameter involving the beach profile should be considered when predicting runup characteristics.

Our results are relevant for a variety of applications where the errors related to empirical formulation obtained by classic regression techniques could be reduced. For instance in the case of coastal hazards, Stockdon et al. (2006) formulation for wave run-up is used by Serafin and Ruggiero (2014) for their extreme total water level estimation and by Bosom and Jimenez (2011) in their framework for coastal hazards assessment. Accuracy in a run-up formulation has consequences for risk and vulnerability assessment in coastal management maps (De Muro et al., 2017; Perini et al., 2016) and other several studies regarding sediment transport (Puleo et al., 2000), swash zone hydrodynamics and morphodynamics (Puleo and Torres-Freyermut, 2016).

\section{Conclusions}

Starting from a large data set covering a wide range of swash, beach and wave field characteristics, we developed two new predictors for total and infragravity swash elevations, using the machine learning technique of genetic programming. We tested and compared our new formulas with previously developed and largely accepted parameterizations of swash (e.g. Stockdon at al., 2006) using independent published data sets. Results of the two GP predictors selected (one for total and one for infragravity swash) show better performance compared with the formulation of Stockdon et al. (2006), evaluated using an independent (unknown to the algorithm) data set (which included extreme highly energetic wave storm, particularly relevant for coastal hazards). This work contributes to reducing the uncertainty in predicting the swash excursion and consequently in assessing the coastal vulnerability and hazards (e.g. inundation) which depend in part upon wave swash (Bosom and Jimenez, 2011). A better prediction of swash excursion could also influence retreat or accommodation strategies and integrated planning for the mitigation of coastal hazards. Furthermore, GP results indicate that the beach slope influences the infragravity component of the swash - GP predictors improve in performance when the beach slope was included. We therefore conclude that beach slope is a relevant parameter when predicting the infragravity component of the swash elevation, even though this is contrary to several previous studies (e.g. Stockdon et al., 2006; Ruessink, 1998; Senechal et al., 2011). ML, and specifically GP, can be a useful tool for data-rich problems, providing robust predictors and possibly also physical insight. The role and importance of the scientist is not reduced or substituted by the machine but instead improved thanks to a powerful data analysis tool.

Data availability. The dataset named "original dataset" in this work is available at Stockdon and Holman (2011). The dataset named "new dataset" in this work comes from experiments published in the following publications: Guedes et al. $(2011,2013)$ and Senechal et al. (2011). The data of the first two publications can be obtained emailing g.coco@auckland.ac.nz

Competing interests. The authors declare that they have no conflict of interest.

Acknowledgements. Marinella Passarella gratefully acknowledges Sardinia Regional Government for the financial support of her PhD scholarship (P.O.R. Sardegna F.S.E. Operational Programme of the Autonomous Region of Sardinia, European Social Fund 2007-2013 - Axis IV Human Resources, Objective 1.3, Line of Activity 1.3.1.). Marinella Passarella gratefully acknowledges the support and funding GLOBUSDOC international placement programme of University of Cagliari. Marinella Passarella and 
Sandro De Muro gratefully acknowledge the support and funding by the project N.E.P.T.U.N.E. (Natural Erosion Prevision Through Use of Numerical Environment) L. R. 7.08.2007, N.7: "Promozione della ricerca scientifica in Sardegna e dell'Innovazione tecnologica in Sardegna". Giovanni Coco funded by a GNS-Hazard Platform grant (contract 3710440). EBG gratefully acknowledges the support of UoA through a PBRF grant.

Edited by: Piero Lionello

Reviewed by: three anonymous referees

\section{References}

Abolfathi, S., Yeganeh-Bakhtiary, A., Hamze-Ziabari, S. M., and Borzooei, S.: Wave runup prediction using M5' model tree algorithm, Ocean Eng., 112, 76-81, 2016.

Atkinson, A. L., Power, H. E., Moura, T., Hammond, T., Callaghan, D. P., and Baldock, T. E. Assessment of runup predictions by empirical models on non-truncated beaches on the south-east Australian coast, Coast. Eng., 119, 15-31, https://doi.org/10.1016/j.coastaleng.2016.10.001, 2017.

Bakhtyar, R., Bakhtiary, A. Y., and Ghaheri, A.: Application of neuro-fuzzy approach in prediction of runup in swash zone, Appl. Ocean Res., 30, 17-27, 2008.

Bosom, E. and Jiménez, J. A.: Probabilistic coastal vulnerability assessment to storms at regional scale - application to Catalan beaches (NW Mediterranean), Nat. Hazards Earth Syst. Sci., 11, 475-484, https://doi.org/10.5194/nhess-11-475-2011, 2011.

Bonakdar, L. and Etemad-Shahidi, A.: Predicting wave run-up on rubble-mound structures using M5 model tree, Ocean Eng., 38, 111-118, https://doi.org/10.1016/j.oceaneng.2010.09.015, 2011.

Camus, P., Mendez, F. J., Medina, R., and Cofino, A. S.: Analysis of clustering and selection algorithms for the study of multivariate wave climate, Coast. Eng., 58, 53-462, https://doi.org/10.1016/j.coastaleng.2011.02.003, 2011.

Cohn, N. and Ruggiero, P.: The influence of seasonal to interannual nearshore profile variability on extreme water levels: Modeling wave runup on dissipative beaches, Coast. Eng., 115, 7992, https://doi.org/10.1016/j.coastaleng.2016.01.006, 2016.

Cox, N., Dunkin, L. M., and Irish, J. L.: An empirical model for infragravity swash on barred beaches, Coast. Eng., 81, 44-50, https://doi.org/10.1016/j.coastaleng.2013.06.008, 2013.

De Muro, S., Ibba, A., Simeone, S., Buosi, C., and Brambilla, W.: An integrated sea-land approach for mapping geomorphological and sedimentological features in an urban microtidal wave-dominated beach: a case study from S Sardinia, western Mediterranean, J. Maps, 13, 822-835, https://doi.org/10.1080/17445647.2017.1389309, 2017.

Dietterich, T.: Overfitting and Undercomputing in Machine Learning, ACM Comput. Surv., 27, 326-327, https://doi.org/10.1145/212094.212114, 1995.

Dickson, M. E. and Perry, G. L.: Identifying the controls on coastal cliff landslides using machine-learning approaches, Environ. Modell. Softw., 76, 117-127, 2016.

Domingos, P.: A few useful things to know about machine learning, Commun. ACM, 55, 78-87, 2012.
Elfrink, B. and Baldock, T.: Hydrodynamics and sediment transport in the swash zone: a review and perspectives, Coast. Eng., 45, 149-167, 2002.

Galelli, S., Humphrey, G. B., Maier, H. R., Castelletti, A., Dandy, G. C., and Gibbs, M. S.: An evaluation framework for input variable selection algorithms for environmental data-driven models, Environ. Modell. Softw., 62, 33-51, 2014.

Goldstein, E. B. and Coco, G.: A machine learning approach for the prediction of settling velocity, Water Resour. Res., 50, 35953601, https://doi.org/10.1002/2013WR015116, 2014.

Goldstein, E. B., Coco, G., and Murray, A. B.: Prediction of wave ripple characteristics using genetic programming, Cont. Shelf Res., 71, 1-15, https://doi.org/10.1016/j.csr.2013.09.020, 2013.

Guedes, R. M. C., Bryan, K. R., Coco, G., and Holman R. A.: The effects of tides on swash statistics on an intermediate beach, J. Geophys. Res., 116, C04008, https://doi.org/10.1029/2010JC006660, 2011.

Guedes, R. M. C., Bryan, K. R., and Coco, G.: Observations of alongshore variability of swash motions on an intermediate beach, Cont. Shelf Res., 48, 61-74, https://doi.org/10.1016/j.csr.2012.08.022, 2012.

Guedes, R. M. C., Bryan, K. R., and Coco, G.: Observations of wave energy fluxes and swash motions on a lowsloping, dissipative beach, J. Geophys. Res., 118, 3651-3669, https://doi.org/10.1002/jgrc.20267, 2013.

Guza, R. T. and Feddersen, F.: Effect of wave frequency and directional spread on shoreline runup, Geophys. Res. Lett., 39, L11607, https://doi.org/10.1029/2012GL051959, 2012.

Guza, R. T. and Thornton, E. B.: Swash oscillations on a natural beach, J. Geophys. Res., 87, 483-491, https://doi.org/10.1029/JC087iC01p00483, 1982.

Holland, K. T. and Holman, R. A.: Statistical distribution of swash maxima on natural beaches, J. Geophys. Res., 98, 10271-10278, 1993.

Holland, K. T. and Holman, R. A.: Field observations of beach cusps and swash motions, Mar. Geol., 134, 77-93, 1996.

Holland, K. T., Raubenheimer, B., Guza, R. T., and Holman, R. A.: Runup kinematics on a natural beach, J. Geophys. Res., 100, 4985-4993, 1995.

Holman, R. A.: Extreme value statistics for wave run-up on a natural beach, Coast. Eng., 9, 527-544, https://doi.org/10.1016/03783839(86)90002-5, 1986.

Holman, R. A. and Sallenger, A.: Setup and swash on a natural beach, J. Geophys. Res., 90, 945-953, https://doi.org/10.1029/JC090iC01p00945, 1985.

Hunt, L. A.: Design of seawalls and breakwaters, P. ASCE, 85, $123-$ $152,1959$.

Kazeminezhad, M. H. and Etemad-Shahidi, A.: A new method for the prediction of wave runup on vertical piles, Coast. Eng., 98, 55-64, https://doi.org/10.1016/j.coastaleng.2015.01.004, 2015.

Knaapen, M. A. F. and Hulscher, S. J. M. H.: Regeneration of sand waves after dredging, Coast. Eng., 46, 277-289, https://doi.org/10.1016/S0378-3839(02)00090-X, 2002.

Koza, J. R.: Genetic Programming, on the Programming of Computers by Means of Natural Selection, MIT Press, Cambridge, 1992.

Masselink, G. and Puleo, J. A.: Swash-zone morphodynamics, Cont. Shelf Res., 26, 661-680, 2006. 
Miche, K.: I.e pouvoir réfléchissant des ouvrages maritimes exposés a l'action de la houle, Ann. Pours Cliaussees, 121, 285-319, 1951.

Nicolae, L. A., Pedreros, R., and Senechal, N.: Wave set-up and run-up variability on a complex barred beach during highly dissipative storm conditions, in: Proceedings of the 14th International Coastal Symposium (Sydney, Australia), edited by: VilaConcejo, A., Bruce, E., Kennedy, D. M., and McCarroll, R. J., J. Coastal Research, 75, 882-886, Coconut Creek (Florida), https://doi.org/10.2112/SI75-177.1 , 2016.

O’Neill, M., Vanneschi, L., Gustafson, S., and Banzhaf, W.: Open issues in genetic programming, Genet. Program. Evol. M., 11, 339-363, https://doi.org/10.1007/s10710-010-9113-2, 2010.

Pape, L., Ruessink, B. G., Wiering, M. A., and Turner, I. L.: Recurrent neural network modeling of nearshore sandbar behavior, Neural Networks, 20, 509-518, https://doi.org/10.1016/j.neunet.2007.04.007, 2007.

Perini, L., Calabrese, L., Salerno, G., Ciavola, P., and Armaroli, C.: Evaluation of coastal vulnerability to flooding: comparison of two different methodologies adopted by the EmiliaRomagna region (Italy), Nat. Hazards Earth Syst. Sci., 16, 181194, https://doi.org/10.5194/nhess-16-181-2016, 2016.

Poate, T., McCall, R., and Masselink, G.: A new parameterisation for runup on gravel beaches, Coast. Eng., 117, 176-190, https://doi.org/10.1016/j.coastaleng.2016.08.003, 2016.

Puleo, J. A. and Torres-Freyermuth, A.: The second international workshop on swash-zone processes, Coast. Eng., 115, 1-7, https://doi.org/10.1016/j.coastaleng.2015.09.007, 2016.

Puleo, J. A., Beach, R. A., Holman, R. A., and Allen, J. S.: Swash zone sediment suspension and transport and the importance of bore-generated turbulence, J. Geophys. Res., 105, 17021-17044, https://doi.org/10.1029/2000JC900024, 2000.

Ruessink, B. G., Kleinhans, M. G., and Van den Beukel, P. G. L.: Observations of swash under highly dissipative conditions, J. Geophys. Res., 103, 3111-3118, https://doi.org/10.1029/97JC02791, 1998.

Ruggiero, P., Komar, P. D., Marra, J. J., McDougal, W. G., and Beach, R. A.: Wave runup, extreme water levels and the erosion of properties backing beaches, J. Coastal Res., 17, 407-419, 2001.

Ruggiero, P., Holman, R. A., and Beach, R. A.: Wave run-up on a high-energy dissipative beach, J. Geophys. Res., 109, C06025, https://doi.org/10.1029/2003JC002160, 2004.

Schmidt, M. and Lipson, H.: Distilling free-form natural laws from experimental data, Science, 324, 81-85, https://doi.org/10.1126/science.1165893, 2009.

Schmidt, M. and Lipson, H.: Eureqa (Version 1.24.0 (build 9367).) [Software], available at: www.nutonian.com/products/eureqa/ (last access: 21 February 2018), 2013.
Senechal, N., Coco, G., Bryan, K. R., and Holman, R. A.: Wave runup during extreme storm conditions, J. Geophys. Res., 116, C07032, https://doi.org/10.1029/2010JC006819, 2011.

Serafin, K. A. and Ruggiero, P.: Simulating extreme total water levels using a time-dependent, extreme value approach, J. Geophys. Res.-Oceans, 119, 6305-6329, https://doi.org/10.1002/2014JC010093, 2014.

Serafin, K. A., Ruggiero, P., and Stockdon, H.: The relative contribution of waves, tides, and non-tidal residuals to extreme total water levels on US West Coast sandy beaches, Geophys. Res. Lett., 44, 1839-1847, https://doi.org/10.1002/2016GL071020, 2017.

Short, A. D.: Handbook of Beach and Shoreface Morphodynamics. Wiley, West Sussex, England, 379, ISBN: 978-0-471-96570-1, 1999.

Stockdon, H. F. and Holman, R. A.: Observations of wave runup, setup, and swash on natural beaches, US Geological Survey Data Series 602, https://pubs.usgs.gov/ds/602/ (last access: 24 February 2018), 2011.

Stockdon, H. F., Holman, R. A., Howd, P. A., and Sallenger Jr., A. H.: Empirical parameterization of setup, swash and runup, Coast. Eng., 53, 573-588, https://doi.org/10.1016/j.coastaleng.2005.12.005, 2006.

Stockdon, H. F., Sallenger Jr., A. H., Holman, R. A., and Howd, P. A.: A simple model for the spatially-variable coastal response to hurricanes, Mar. Geol., 238, 1-20, https://doi.org/10.1016/j.margeo.2006.11.004, 2007.

Tinoco, R. O., Goldstein, E. B., and Coco, G.: A data-driven approach to develop physically sound predictors: application to depth-averaged velocities on flows through submerged arrays of rigid cylinders, Water Resour. Res., 51, 1247-1263, https://doi.org/10.1002/2014WR016380, 2015.

Vousdoukas, M. I., Ferreira, P. M., Almeida, L. P., Dodet, G., Psaros, F., Andriolo, U., Taborda, R., Silva, A. N., Ruano, A., and Ferreira, O. M.: Performance of intertidal topography video monitoring of a meso-tidal reflective beach in South Portugal, Ocean Dynam., 61, 1521-1540, 2011.

Vousdoukas, M. I., Wziatek, D., and Almeida, L. P.: Coastal vulnerability assessment based on video wave run-up observations at a mesotidal, steep-sloped beach, Ocean Dynam., 62, 123-137, 2012.

Yates, M. L. and Le Cozannet, G.: Brief communication "Evaluating European Coastal Evolution using Bayesian Networks", Nat. Hazards Earth Syst. Sci., 12, 1173-1177, https://doi.org/10.5194/nhess-12-1173-2012, 2012. 